\title{
Polycation-globular protein complex: Ionic strength and chain length effects on the structure and properties
}

https://doi.org/10.1515/epoly-2019-0014

Received July 25, 2018; accepted September 28, 2018.

\begin{abstract}
The effect of high salt concentration and $\mathrm{pH}$ on the binding of globular protein to polycation at different molar masses has been investigated by dynamic light scattering (DLS), turbidimetry and electrostatic modeling for the protein. In dilute concentration regime, DLS and $\mathrm{pH}$ titrations showed three remarkable $\mathrm{pH}$ transitions: $\mathrm{pH}_{\mathrm{c}}$, the $\mathrm{pH}$ where soluble complexes of bovine serum albumin (BSA) and linear synthetic Polyethylenemine (PEI) are formed, $\mathrm{pH}_{\mathrm{c}}$ ' presents the end of primary soluble complex and $\mathrm{pH}_{\phi}$ presents the first appearance of microcoacervate droplets. All pH transitions increase with increasing $\mathrm{NaCl}$ concentration. The Adaptive Poisson-Boltzmann Solver (APBS) identify with precision the functional sites at the surface of BSA and shows that the strength of electrostatic interactions depends hugely on the variation of $\mathrm{pH}$ and ionic strength. At a very high concentration of salt, no remarkable effect on a mixture formed of a long chain of polycation and globular protein.
\end{abstract}

Keywords: protein-polycation complex; turbidity; dynamic light scattering; electrostatic potential; ionic strength effect

\footnotetext{
* Corresponding author: Adel Aschi, Université de Tunis El Manar, Faculté des Sciences de Tunis, LR99ES16 Laboratoire Physique de la Matière Molle et de la Modélisation Électromagnétique, 2092, Tunis, Tunisia, e-mail: aschi13@yahoo.fr.

Eya Hergli, Université de Tunis El Manar, Faculté des Sciences de Tunis, LR99ES16 Laboratoire Physique de la Matière Molle et de la Modélisation Électromagnétique, 2092, Tunis, Tunisia.
}

\section{Introduction}

In recent years, several studies have shown that the associative interaction between proteins and polyelectrolytes makes it possible to control the texture, structure and properties of many food products (1-8). As a result, various protein/polyelectrolyte systems have been studied for their practical applications in food technology such as protein separation, increasing thermal stability or acid of proteins, and stabilization of foam emulsions. In fact, the addition of polyelectrolytes to a solution composed of mineral particles can also stabilize these latter or encapsulate them for delivery. The encapsulation procedures are also useful in food processing, where these particles are proteins. An abundant literature proves that the character of the protein/ polyelectrolyte interactions is affected by environmental factors, in particular $\mathrm{pH}$ and ionic strength (9-12). Indeed, the formed complex is based on electrostatic interactions between opposite charges of polyelectrolyte and protein.

Dubin and co-author, in a study of complexes formed by polycations and proteins, have shown that cationic polyelectrolytes can provide a stronger binding affinity and in addition a large binding amount for acid proteins (13-17). The strength of electrostatic interactions depends hugely on the variation of $\mathrm{pH}$ and ionic strength. Indeed, three critical $\mathrm{pH}$-induced structural transitions, $\mathrm{pH}_{\mathrm{c}}$ (formation of primary soluble complex), $\mathrm{pH}_{\mathrm{c}}{ }^{\prime}$ (end of primary soluble complex) and $\mathrm{pH}_{\phi}$ (first appearance of microcoacervate droplets), were identified (13-17).

In this paper, the objective is to characterize the interactions between proteins and cationic polyelectrolytes using the Bovine Serum Albumin (BSA)-synthetic Polyethylenemine (PEI) system.

Recently, Polyethylenimine is used as a polymer for neutralization of the excessiveanionic chargesin particular in colloidal suspensions and as cosmetic products, as for example, as thickener ingredient (viscosity adjuster) $(18,19)$. Still, PEI was intensely used as a drug delivery 
system in recent anti-cancer therapies $(20,21)$. The effect of $\mathrm{pH}$ and ionic strength on binding of BSA protein onto cationic PEIs was observed by turbidimetric titration, dynamic light scattering (QELS). QELS method provides information about the overall hydrodynamic structure of the complex (hydrodynamic dimension). In particular, the computational method of the electrostatic potential of BSA is another way to know and to identify the functional sites situated at the surface of a protein. This later may be visualized by color-coding the molecular surface versus the potential values. In fact this part of extended work have as objective to know with precisely how PEI binds to BSA where these macromolecules have the same sign of charges.

\section{Materials and methods}

\subsection{Materials}

Bovine serum albumin (BSA) (essential fatty acid free) is purchased from Sigma Chemical Co and is a large globular protein with a molecular weight $=67 \mathrm{kDa}$ and contains 585 amino acids. In each solution, the concentration $c$ of purified BSA was accurately measured using absorbance spectroscopy. The absorbance $A$, at $278 \mathrm{~nm}$, is a linear function of the molar concentration $c$, according to the known Beer-Lambert law (22):

$$
A=\varepsilon l c,
$$

where $\varepsilon$ is the molar absorption coefficient and $l$ is the cell path length.

The used protein concentration of complex for this study was typically around $0.1 \%(\mathrm{w} / \mathrm{v})$.

The polycation used in our experiments was a linear Polyethylenimine (PEI). The molar masses of polyethylenemine used are $2.5 \mathrm{kDa}$ and $25 \mathrm{kDa}$ and polydispersities for these couple of masses are $\leq 1.2$. These Polycations were obtained from Sigma Aldrich. In this work, the mass ratio protein/ polycation whose expression is given by $r=[\mathrm{BSA}] /[\mathrm{PEI}]$ was set at 5 .

In order to vary the $\mathrm{pH}$, the mixture composed by BSA and PEI was adjusted by the addition of a strong base $(\mathrm{NaOH})$ or a strong acid $(\mathrm{HCl})$ and measured with accuracy pH-meter (multi-parameter analyzer Consort C862. This $\mathrm{pH}$-meter offering a resolution up to $0.001 \mathrm{pH}$ unit. A pH electrode (SP10T, $3 \mathrm{M} \mathrm{KCl,} \mathrm{pH}$ ranged from 0 to 14. Temperature compensation: $0^{\circ} \mathrm{C}$ to $80^{\circ} \mathrm{C}$ ) was immersed for $10 \mathrm{~h}$ more in $3 \mathrm{M}$ of $\mathrm{KCl}$ solution and it was calibrated at
3 points $(\mathrm{pH}=4, \mathrm{pH}=7$ and $\mathrm{pH}=10)$. After mixing, the ionic strength was adjusted by adding $\mathrm{NaCl}$. In fact, the mixture was stirred for $3 \mathrm{~min}$ to obtain a colloidal solution. Finally, the stock solutions were stored at $4^{\circ} \mathrm{C}$. Measurements of $\mathrm{pH}$, turbidity, and hydrodynamic radius performed $24 \mathrm{~h}$ after mixing. For some samples, these measurements were repeated after one week to ensure the stability of the complexes.

$\mathrm{NaCl}$ was purchased from Sigma-Aldrich. $\mathrm{HCl}$ and $\mathrm{NaOH}$ were purchased from Merck. Distilled water was used throughout the experiments.

\subsection{Characterization of the samples}

\subsubsection{Dynamic light scattering measurements}

The DLS measurements were carried out with a home-built goniometer and are performed in the homodyne mode, using the green line (533 nm, $100 \mathrm{~mW}$ ) of laser (Spectra Physics). The intensity of scattered light was detected by a photomultiplier detector (Hamamatsu H7155-01). A digital correlator (Flex02-12D/C) equipped with 1088 channels are used to determine the intensity-intensity autocorrelation function $g_{2}(t)$. The solutions were set into cylindrical lightscattering cuvettes.

All scattering experiments, which are described below, are performed at $90^{\circ}$ scattering angle and at ambient temperature (i.e., $24^{\circ} \mathrm{C}$ ). Dynamic light scattering (DLS) or quasi-elastic light scattering (QELS) measurements have been performed in the so-called parallel mode, which allows measurements of the correlation function over a wide time range on a logarithmic scale. In this mode relaxation time, $\tau$ that differ by orders of magnitude can be probed in a single measurement. The measured intensity autocorrelation functions are related to the field autocorrelation function $g_{1}(t)$ through the Siegert relation (23):

$$
g_{2}(t)=1+\beta\left|g_{1}(t)\right|^{2}
$$

where, $0<\beta<1$ is a constant depending on the experimental setup.

For complexes, the decays of the field correlation functions were always found to be bimodal:

$$
g_{1}(t)=A_{f} \exp \left(-t / \tau_{f}\right)+A_{s} \exp \left(-t / \tau_{s}\right)
$$

where $\mathrm{A}_{f}+A_{s}=1$. The parameters $\tau_{f}$ and $\tau_{s}$ are the fast and slow relaxation times, respectively.

In fact, the cooperative mode or fast mode relaxation " $\tau_{f}$ '”(24) reflects the predominance of concentration fluctuations, whereas the slow mode is difficult to 
characterize (reptation modes of individual chains or diffusion of short structural domains due to the interchain interaction with a large correlation length) (24).

$\tau_{f}$ is related to the apparent translational diffusion coefficient $D_{\text {app }}$ by the following relationship:

$$
D_{\text {app }}=1 /\left(\mathrm{q}^{2} \tau_{f}\right)
$$

The scattering wave vector $q$ is given by $q=4 \pi n / \lambda \times \sin (\theta / 2)$, where $n$ is the refractive index and $\theta$ the diffusion angle.

For non-interacting rigid spheres (ideal solution), the apparent hydrodynamic radius $R_{\text {Happ }}$ is defined by the Stokes-Einstein equation:

$$
R_{\text {Hарp }}=R_{\mathrm{H}}=\frac{k_{\mathrm{B}} T}{6 \pi \eta D_{\text {app }}}
$$

where $K_{\mathrm{B}}$ is the Boltzmann's constant, $T$ is the absolute temperature and $\eta$ is the solvent viscosity. Note, in all experimental results $R_{\text {Happ }}$ is referred to $R_{\mathrm{H}}$.

All DLS measurements were repeated at least 5 times and the results are presented together with their standard deviation.

\subsubsection{Turbidity measurements}

Turbidity measurements were carried out with visible spectrophotometer at a fixed wavelength of $514 \mathrm{~nm}$ (i.e. similar to the laser wavelength used for dynamic light scattering measurements) with $1 \mathrm{~cm}$ path length cuvette. In fact, none of the used macromolecules in the solution absorb light at this wavelength, which signifies that the measurement of turbidity can be related to the extent of complex formation. All measurements were conducted at room temperature $\left(20^{\circ} \mathrm{C}\right)$, and the turbidity was then reported as $100-T \%$, where $T$ is the sample transmittance. The transmittance $T$ of the samples could be determined from the following relationship: $T=I_{t} / I_{0}$, where $I_{\mathrm{t}}$ is the transmitted light intensity of solution and $I_{0}$ is the light intensity for solvent only. Measurements were made in triplicate.

\section{Results}

\subsection{Effect of salt on rate charge}

Generally, the dissociation of the polycation strongly depends on the rate charge and allowed to quantitatively account the charge evolution as a function of the $\mathrm{pH}$. For this, before studying the effect of salt on the complex formed by PEI and BSA, we studied the rate charge of the polyelectrolyte alone versus $\mathrm{pH}$. In solution, the polyelectolyte $\mathrm{BOH}$ may be dissolved into ions $\mathrm{B}^{+}$and $\mathrm{OH}^{-}$according to the following chemical reaction and Henderson-Hasselbalch equation:

$$
\mathrm{BOH}<=>\mathrm{B}^{+}+\mathrm{OH}^{-}
$$

The rate charge $f$ can be defined as:

$$
f=\beta+\frac{10^{-p H}}{C_{m B}}\left(10^{-2 p H}-1\right)
$$

where, $\beta$ is the neutralization rate equal to, $\beta=\frac{[\mathrm{NaOH}]}{[\mathrm{BOH}]+\left[\mathrm{B}^{+}\right]}=\frac{[\mathrm{NaOH}]}{C_{m B}}$.
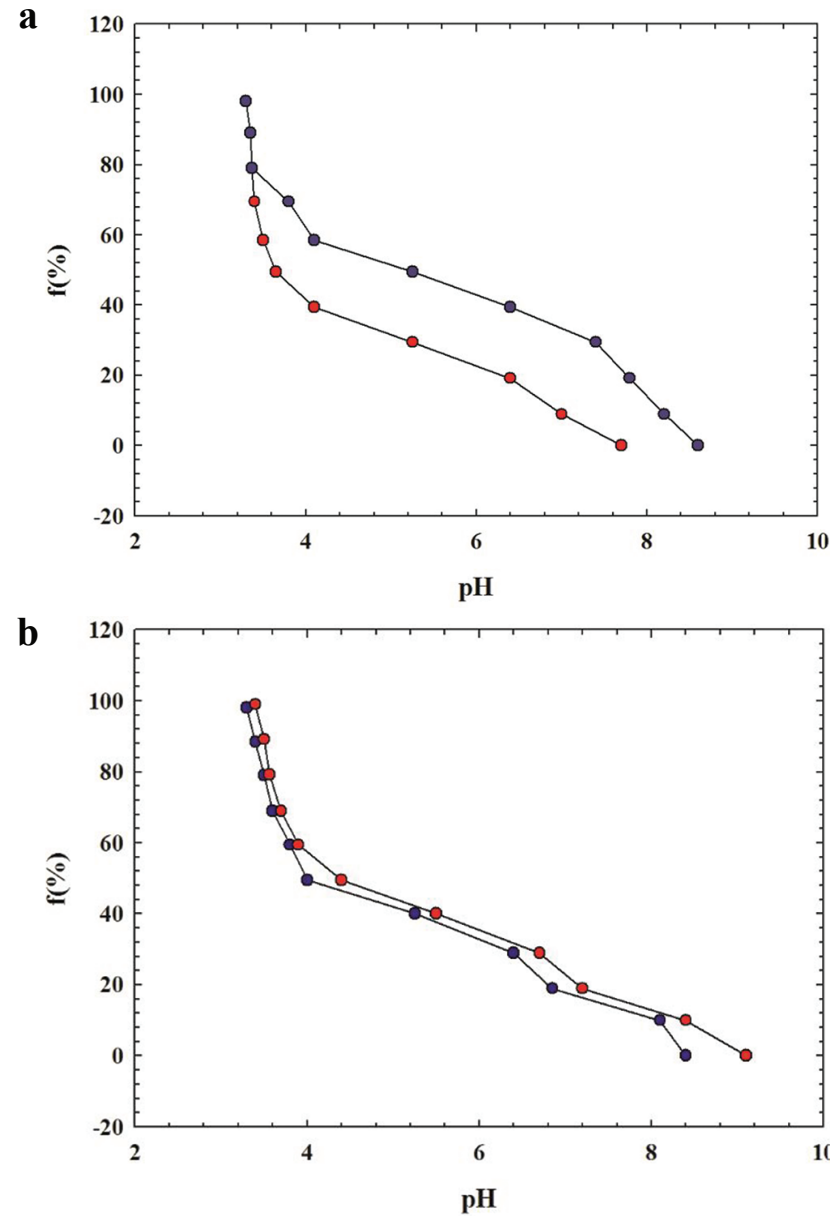

Figure 1: Evolution of rate of charge $f$ versus $\mathrm{pH}$ in the presence $(\bullet,[\mathrm{NaCl}]=0.15 \mathrm{M})$ and in the absence $(\bullet,[\mathrm{NaCl}]=0 \mathrm{M})$ of the salt $(\mathrm{NaCl})$ for molar mass of polycation equal to $2.5 \mathrm{kDa}$. 
We present, in Figures $1 \mathrm{a}$ and $1 \mathrm{~b}$, the evolution of the rate of charge $f$ versus $\mathrm{pH}$ in the presence and in the absence of the salt $(\mathrm{NaCl})$ for two molar masses of polycation, $2.5 \mathrm{kDa}$ and $25 \mathrm{kDa}$. The rate charge is inversely proportional to $\mathrm{pH}$ i.e. an increase in $\mathrm{pH}$ causes a decrease of $f$. We remarked that the polymer, with $\mathrm{Mw}=25 \mathrm{kDa}$, not affected by the presence of salt at $0.15 \mathrm{M}$, Figure $1 \mathrm{~b}$, unlike the case where the molar mass equal to $2.5 \mathrm{kDa}$. In fact, the effect of presence of salt depends on the length of polyethelenimine.

\subsection{Study of complex formation BSA-PEI (25 kDa)}

\subsubsection{Turbidity variation of the complex BSA-PEI}

The variation of the turbidity of the mixture of PEI ( $25 \mathrm{kDa})$ and BSA for a ratio $\mathrm{r}=\mathrm{Pr}: \mathrm{Pl}=5: 1$ versus $\mathrm{pH}$ is presented in Figure 2a. In fact, we remind, that turbidity is given by the following relation:

$$
A=100-T \%
$$

where $A$ is the absorbance and $T$ is the transmission.

As a first step, for $\mathrm{pH}$ values lower than 4.6 , the turbidity is stable and not changed significantly by the quantity of the added $\mathrm{NaOH}$. By adding more $\mathrm{NaOH}$ to bring the $\mathrm{pH}$ to value above 4.6, the turbidity increases gradually until $\mathrm{pH}$ value about equal to 7.3 . After this last value of $\mathrm{pH}$ i.e. above $\sim 7.3$, the turbidity significantly evolves and reaches rapidly a value equal to 8.7. Finally, the turbidity varies weakly, reaches almost a plateau for $\mathrm{pH}>8.7$, and regarded as the endpoint of the titration.

We can estimate that $\mathrm{pH}=4.6$, below the isoelectric point $\mathrm{pH}_{\mathrm{i}} 4.9$, corresponds to the $\mathrm{pH}_{\mathrm{c}}$, which corresponds to the formation of soluble complex.

It has shown that the formation of macromolecular complexes can be detected at $\mathrm{pH}_{\mathrm{c}}$ lower than the $\mathrm{pH}_{\mathrm{i}}$ of the protein, where both macromolecule species have the same sign of charges. Such a phenomenon had already been reported by Mattison when studying the interaction between poly(dimethyldiallylammonium chloride) (PDMDAAC) and Bovine serum (17). The formation of complexes, under these conditions, is attributed to the attraction between polycation charges and oppositely charged patches on the protein surface (9).

The value of $\mathrm{pH}=7.3$ represents the phase separation, where the soluble complex formation is completed, and called $\mathrm{pH}_{\mathrm{c}}$ ' and $\mathrm{pH}_{\phi}$ corresponds to formation of the first appearance of microcoacervate droplets.

In fact, four regions can be defined in Figure $2 \mathrm{a}$. These four transition regions $\left(\mathrm{pH}_{\mathrm{c}}, \mathrm{pH}_{\mathrm{c}}{ }^{\prime}\right.$ and $\left.\mathrm{pH}_{\phi}\right)$ were determined by the intersections of the two tangents. The region 1 corresponds to $\mathrm{pH}<\mathrm{pH}_{\mathrm{c}}$ where the Coulomb repulsive forces between the positive charges carried by the protein and the polycation, prevent the formation of the complex, resulting macroscopically in a roughly constant turbidity. In region $2\left(\mathrm{pH}_{\mathrm{c}}<\mathrm{pH}<\mathrm{pH}_{\mathrm{c}}\right)$ PEI and BSA are ionized and bear opposite charges, marked by the formation of soluble complexes and causing the turbidity to increase but very slightly. In the region 3 $\left(\mathrm{pH}_{\mathrm{c}^{\prime}}<\mathrm{pH}<\mathrm{pH}_{\phi}\right)$ the turbidity increases rapidly. The last region corresponds to $\mathrm{pH}>\mathrm{pH}_{\phi}$, where constant values of turbidity are observed, which is indicative of the phase separation of the system and therefore the presence of coacervates.

This result is in agreement with the study by Kaibara et al. who analyzed the BSA/ poly-(dimethyldiallylammonium chloride) (PDADMAC) mixture and showed the existence of four distinct regions of $\mathrm{pH}$ as illustrated by the evolution of turbidity as a function of $\mathrm{pH}$ (Figure 2a) (25).

\subsubsection{Variation of the hydrodynamic radius of the complex BSA / PEI}

Figure $2 \mathrm{~b}$ shows the variation of apparent hydrodynamic radius $R_{\mathrm{H}}$ of mixture BSA/PEI ( $25 \mathrm{kDa}$ ) versus $\mathrm{pH}$. The apparent hydrodynamic radius variation consists of three branches:

- At pH values between 3.2 and 4.6, the $R_{\mathrm{H}}$ is constant and roughly equal to $4.2 \mathrm{~nm}$. This value corresponds to the size of the BSA protein alone.

- At pH values between 4.6 and 7, $R_{\mathrm{H}}$ increases linearly from 4.2 to $5.4 \mathrm{~nm}$. This result means that from the $\mathrm{pH}=4.6$ the soluble complex begins to establish. In addition, since the molar mass of the added polycation is low, compared to that of the BSA, the size of the primary complex obtained in this $\mathrm{pH}$ range is small. We can still estimate that $\mathrm{pH} \cong 4.6$ is the $\mathrm{pH}_{c}$ and $\mathrm{pH}_{\mathrm{c}} \cong 7$.

- At $7<\mathrm{pH}<8.7$, the hydrodynamic radius increases rapidly and reaches $50 \mathrm{~nm}$.

- At $\mathrm{pH}>8.7$, the solution becomes very turbid and with dynamic light scattering technique, it is difficult to determine with precisely the particle size, due to the multiple scattering effect or strong light absorption. 

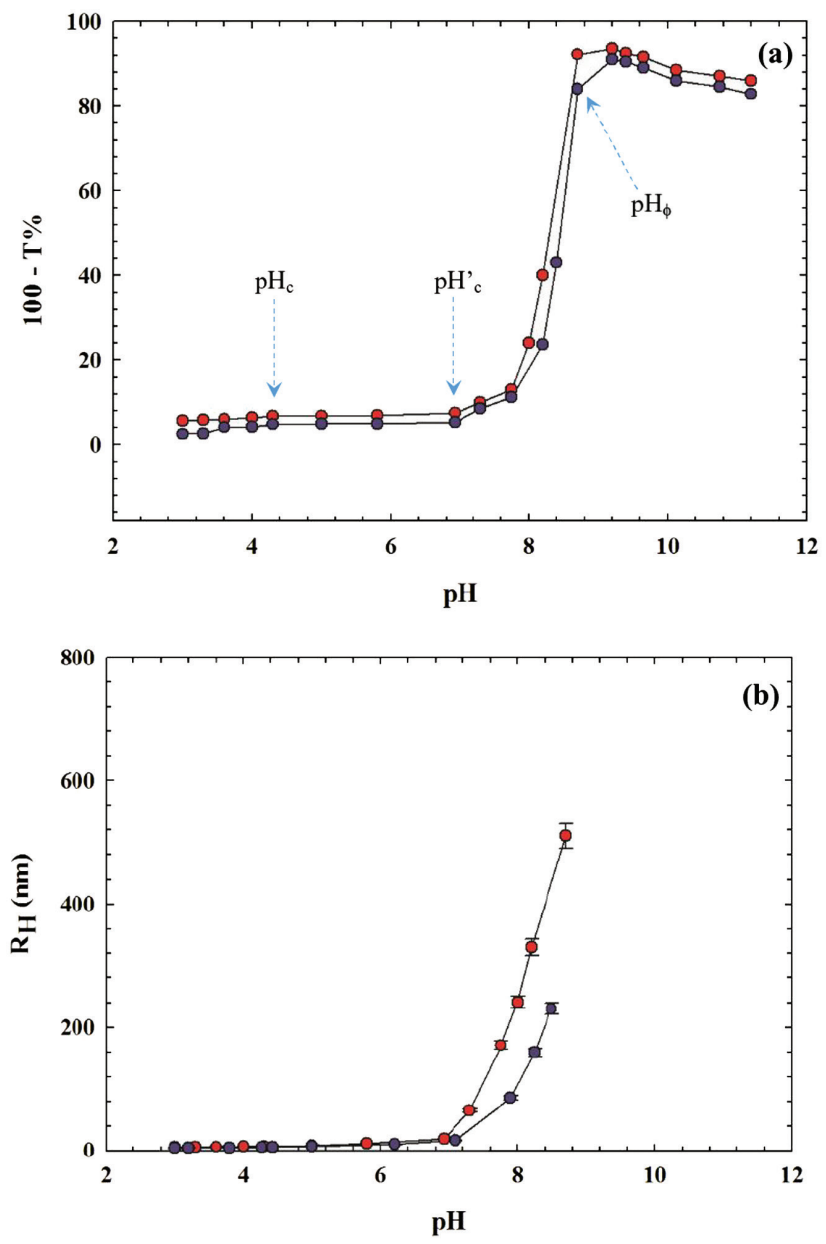

Figure 2: Acid base titration at various salt concentrations of mixture of BSA/PEI ( $25 \mathrm{kDa}$ ) at $\mathrm{Pr}: \mathrm{Pl}=5: 1$. (a) Turbidity of the complex vs $\mathrm{pH}$. (b) Hydrodynamic radius of the complex vs $\mathrm{pH}$. The arrows show the $\mathrm{pH}$ transitions. $\bullet,[\mathrm{NaCl}]=0 \mathrm{M} ; \bullet,[\mathrm{NaCl}]=0.15 \mathrm{M}$.

\subsubsection{Effect of salt on complex formation}

Like $\mathrm{pH}$, the addition of an amount of salt in a medium is an important factor, which can affect the degree of ionization and therefore the complexation and phase separation of the weak polyelectrolytes.

In order to analyze the salt effect on the formation of complex BSA-polycation, we added a $0.15 \mathrm{M}$ of $\mathrm{NaCl}$ to the samples.

We show in Figures $2 \mathrm{a}$ and $2 \mathrm{~b}$ the variation of turbidity and hydrodynamic radius of the system, formed by the mixture of BSA and polycation, with and without salt in the solution.

From these figures, it can be seen that the turbidity and the hydrodynamic radius begin to evolve at $\mathrm{pH}<\mathrm{pH}_{\mathrm{i}}$ values of BSA for the two systems in the absence and presence of salt. In addition, the turbidity increases in a similar way to that of $R_{\mathrm{H}}$ when the $\mathrm{pH}$ increases.
By comparing the results obtained for the variation of the hydrodynamic radius in the presence and absence of the salt as well as those of the variation of the turbidity, it noted that the curves present a small shift. We can conclude that the electrostatic screening has weak effect. Indeed, $\mathrm{pH}_{\mathrm{c}}, \mathrm{pH}_{\mathrm{c}}$ ' and $\mathrm{pH}_{\phi}$ are increased to a value about 0.3 as the $\mathrm{NaCl}$ concentration increases. This result is quite contrary to that obtained by Clitor J.F. Souza et al. and Bram L.H.M. Sperber et al. $(26,27)$, even if the shift is the same, where they have studied the effect of ionic strength on a mixture of protein with polyanion. In addition, Andrea Salis et al. showed, in a study on the effect of $\mathrm{NaCl}$ on charge of BSA, that the $\mathrm{pH}_{\mathrm{i}}$ increases by increasing the ionic strength (see Figure 4b) (28). In another study, Tolstoguzov showed that the main forces responsible for the interactions between proteins and polyelectrolytes are electrostatic in nature, so the ionic strength has a great effect on interactions (29). The concentration of salts also influences the electrostatic interactions and the compatibility of the molecules since the ions can block the reagents sites of the polymers, reducing their rate charge and favoring the association between proteins, occasioning the incompatibility between the two polyelectrolytes (30). Finally, after these interpretations, we can still conclude that polycation plays an inverse role as a polyanion.

\subsection{Study of the formation of the complex BSA/PEI (2.5 kDa)}

In the previous part, we examined the effect of salt on a system containing BSA-PEI mixture for a molar mass of PEI equal to $2.5 \mathrm{kDa}$, the ratio $\mathrm{r}=5$ and $\mathrm{T}=25^{\circ} \mathrm{C}$. We represent in the following Figure 3, the evolution of turbidity $(100-T \%)$ and hydrodynamic radius $R_{\mathrm{H}}$ in the presence and absence of the salt:

As Figure 2a, Figure 3a shows four regions, separated by $\mathrm{pH}_{\mathrm{c}}, \mathrm{pH}_{\mathrm{c}}{ }^{\prime}$ and $\mathrm{pH}_{\phi}$, and which have been still determined by the intersections of the two tangents. In fact, these regions represent the stability and instability of a mixture of PEI/BSA. In this figure, not all $\mathrm{pH}$ transition are changed, except in presence of $\mathrm{NaCl}$ where the $\mathrm{pH}$ gap is enormous $\left(\mathrm{pH}_{0 \mathrm{M}}-\mathrm{pH}_{0.15 \mathrm{M}} \cong 2\right)$. If we compare the result with that obtained in Figure 2a, this phenomenon may be due to presence of weak molecular mass of PEI $(2.5 \mathrm{kDa})$ and high salt concentration, where the BSA protein loss their attractive forces and is released from PEI. Indeed, the turbidity and the hydrodynamic radius curves of the mixture at $0.15 \mathrm{M}$ of $\mathrm{NaCl}$ show that the electrostatic screening is clearly noticeable. As mentioned before, in presence of salt, the turbidity and $R_{\mathrm{H}}$ evolutions 

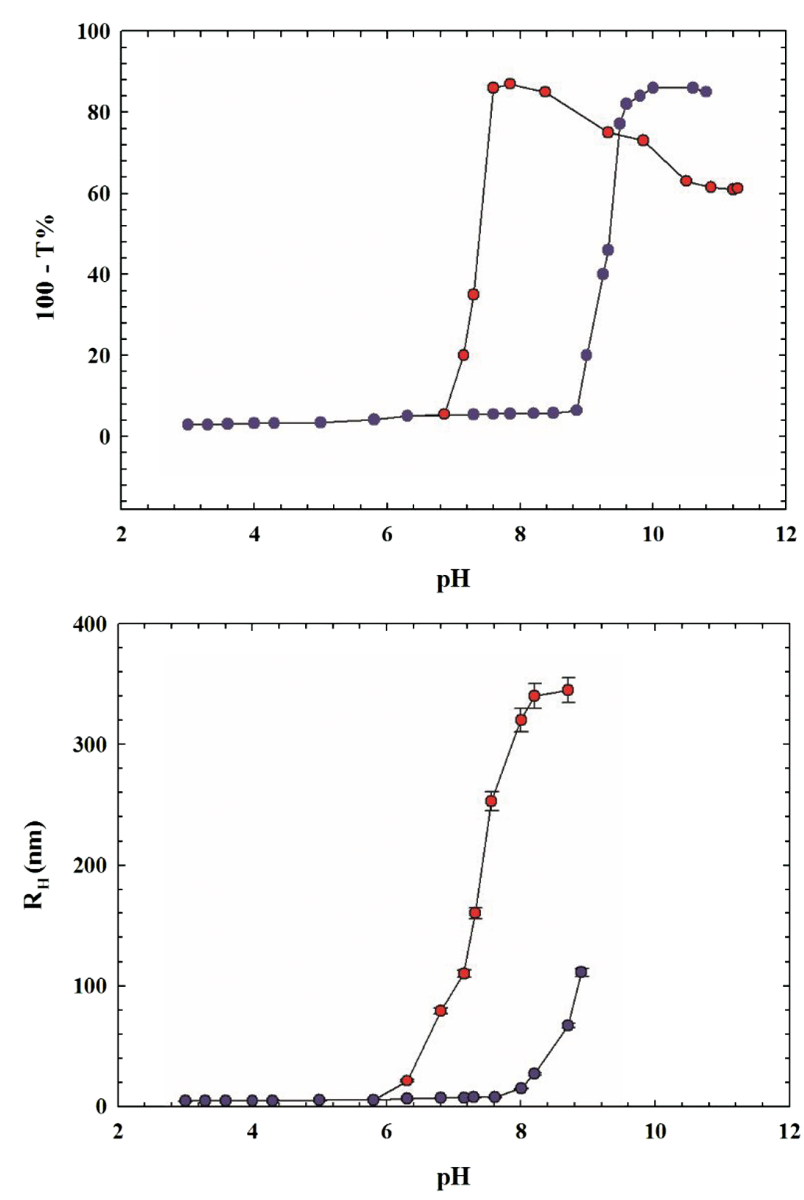

Figure 3: Acid base titration at various salt concentrations of mixture of BSA/PEI (2.5 kDa) at Pr:Pl=5:1. (a) Turbidity of the complex vs $\mathrm{pH}$. (b) Hydrodynamic radius of the complex vs $\mathrm{pH}$. The arrows show the $\mathrm{pH}$ transitions. $\bullet[\mathrm{NaCl}]=0 \mathrm{M} ; \bullet,[\mathrm{NaCl}]=0.15 \mathrm{M}$.

start at a pH much higher than that without salt. These evolutions are noticeable for $\mathrm{pH}$ values higher than $\mathrm{pH}_{\mathrm{i}}$ of BSA (4.6), regardless the presence or not of salt. Indeed, at $\mathrm{pH}_{\mathrm{c}}$, a small increase in turbidity was observed, which indicates the start of the formation of soluble complex. At this region, the binding of BSA onto PEI may due to the attraction between positive PEI and negative "charge patch" of BSA i.e. the change in the pKa of BSA induced by the electric field of the PEI (9). For $\mathrm{pH}_{\mathrm{c}}<\mathrm{pH}<\mathrm{pH}_{\mathrm{c}}$, the turbidity and the hydrodynamic radius increase slightly when the $\mathrm{pH}$ increases. In this region, the size of the soluble complex is the same compared to that obtained for the molar mass of $\mathrm{PEI}=25 \mathrm{kDa}$. For $\mathrm{pH}_{\mathrm{c}}{ }^{\prime}<\mathrm{pH}<\mathrm{pH}_{\phi}$ an abrupt increase in turbidity values and on the other hand, the hydrodynamic radius not be detectable with precision because the solution is very turbid (not transparent). For $\mathrm{pH}>8$ and $\mathrm{pH}>9$, the solution becomes turbid and the formation of coacervates obtained for the cases of $0 \mathrm{M}$ and $0.15 \mathrm{M}$ of salt respectively. Moreover, with the standard scattering technique used in our work, the hydrodynamic radius cannot be determined with precision due the problem cited before. In fact, at very high $\mathrm{pH}$ and salt concentration, the polycation can behave like an aggregate and this result has been confirmed with that obtained by Kimberly A Curtis et al. (31). Indeed, these authors, in a study of the effect of salt and $\mathrm{pH}$ on the change in PEI conformation $2.5 \mathrm{kDa}$, showed that this polycation passes from a high intra-chain repulsion conformation to low intra-chain repulsion conformation or aggregate when $\mathrm{pH}$ and salt increase and the polycation charges increase with decreasing $\mathrm{pH}$, whereas the charge repulsion is screened by increasing the salt concentration.

\section{Computational methods}

In this part of work, we studied the electrostatic potential of protein (BSA). The electrostatic potential can identify the functional sites at the surface of a protein and can be showed by color-coding of the molecular surface as function of potential values. In reality, this work helps us to know with precision how polyelectrolyte binds with the protein mainly at $\mathrm{pHc}$, where the charges of the protein and of the polyelectrolyte are the same.

In order to analyze the effects of ionic strength, the electrostatic potential was determined at $0 \mathrm{M}$ and $0.15 \mathrm{M}$ $\mathrm{NaCl}$ salt concentration and assuming +1 and -1 charges for counter-ions. The protein crystal structures with Protein Data Bank identifications 3V03 (BSA)were taken from the RCSB Protein Data Bank (http://www.rcsb.org).

In fact, according to the PARSE force field, electrostatic potential and van der Waals radius were done with PDB2PQR web portal (http://nbcr-222.ucsd.edu/ pdb2pqr_2.1.1/). The probe radius $r$ for ion accessibility and surface dielectric surface were set to be $2.0 \AA$ and $1.4 \AA$, respectively. The system temperature $T$ was fixed to $298.17 \mathrm{~K}$. In addition, PDB2PQR uses PROPKA (32) to attribute protonation states at desired $\mathrm{pH}$. The linear Poisson-Boltzmann Solver (APBS) through Opal web service, which is inserted in UCSF Chimera software (http://nbcr-222.ucsd.edu/opal2/services/apbs_1.3) was used to calculate the electrostatic potential. All isopotential contours were plotted at $\pm 1 \mathrm{~K}_{\mathrm{B}} \mathrm{T} / \mathrm{e}$ by taking 78.54 and 2 for dielectric constants of the solvent and the protein respectively.

The net charge and folding free energy of protein at different $\mathrm{NaCl}$ salt concentrations were estimated from Bluues web server (http://protein.bio.unipd.it/bluues/).

The Bluues version 2.0 generated plots showing (a) the change of folding free energy and (b) total charge $\mathrm{Zp}$ 
with the increase in $\mathrm{pH}$ (Figures $4 \mathrm{a}$ and $4 \mathrm{~b}$ ). All figures were obtained at different $\mathrm{NaCl}$ salt concentrations ( 0 and $0.15 \mathrm{M}$ ). The titration results showed that the folding free energy of the protein, was almost low in the $\mathrm{pH}$ range 5.0-11.0 (Figure 4a), which indicates that the protein stable in this particularrange. In a study on thestability of a human calcium/calmodulin-dependent kinase IV protein, Huma Naz et al. found the same result by MD simulations (33). In addition, in this range of $\mathrm{pH}$, no remarkable effects when the salt concentration increased.

An alternative way of addressing the same problem is to calculate the total charges Zp of BSA (Figure 4b). In fact, at the extremes of $\mathrm{pH}$ range, this protein presents high density of charges (BSA highly charged), a huge positive charge at acidic $\mathrm{pH}$ and huge negative charge at basic $\mathrm{pH}$. With an increasing salt concentration, the calculated values of total charge of the BSA increase at the edges of the $\mathrm{pH}$ range, which reflect a higher number of de/protonation of acidic and basic residues at higher and
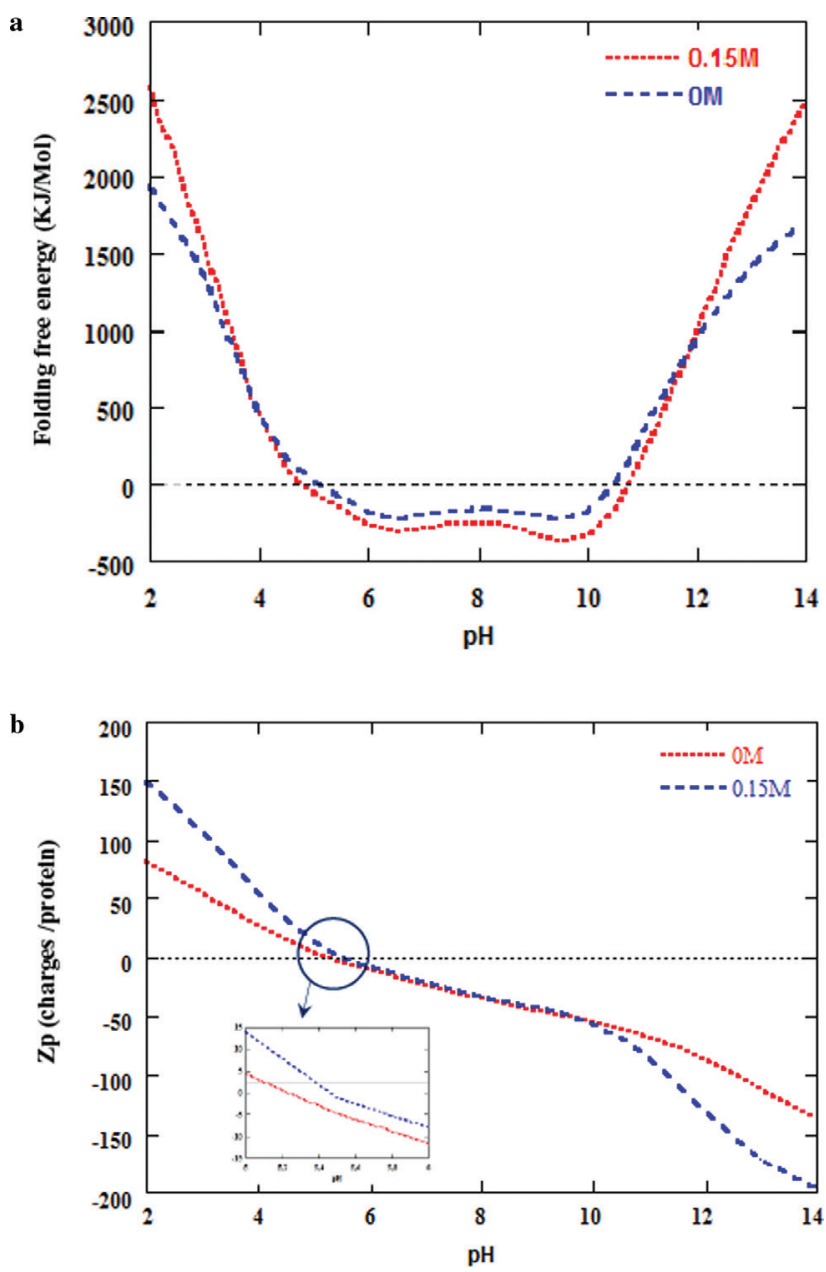

Figure 4: Change of folding free energy (a) and total charge Zp (b) of $\mathrm{BSA}$ versus $\mathrm{pH}$ and at different $\mathrm{NaCl}$ salt concentrations ( 0 and $0.15 \mathrm{M})$. lower $\mathrm{pH}$ values, respectively. Indeed, the $\mathrm{pH}$ values close to the point of zero charge (protein isoelectric point (IEP)) are presented in the inset of Figure 4b. In presence of salt, the isoelectric point is practically shifted more than half a $\mathrm{pH}$ unit towards basic $\mathrm{pH}$. Our results for bovine serum albumin protein total charge in the presence of salt concentration are in good agreement with the papers published by Jachimska and co-workers (34), where these authors found, by zeta potential $(\zeta)$ measurement that the IEP of BSA increases with increasing salt $\mathrm{NaCl}$ concentration.

Figure 5 shows the anisotropies of the electrostatic potential contour around the Bovine Serum Albumin (3V03) as a function of $\mathrm{pH}\left(\mathrm{pH}_{c}, \mathrm{pH}_{\mathrm{c}}{ }^{\prime}\right.$ and $\left.\mathrm{pH}_{\phi}\right)$ and salt $\mathrm{NaCl}$ concentration. These images portray BSA as "electrostatically seen" by a polycation and clearly reveal the dipolar asymmetry of the presented protein. The values of electrostatic potential are color-coded from red for $-1 K_{\mathrm{B}} T / e$ to blue for $+1 K_{\mathrm{B}} T / e$ on the molecular surface. In fact, these results help us to know, with precisely, the $\mathrm{pH}$ and ionic strength dependence of the complexation observed in Figures 2 and 3 and the comparison of the electrostatic potential on the surface of BSA. Indeed, to facilitate the comparison, the protein is presented in the same orientation for all the least cases. In Figure 5, we find that when the $\mathrm{pH}$ increases the number of negatively
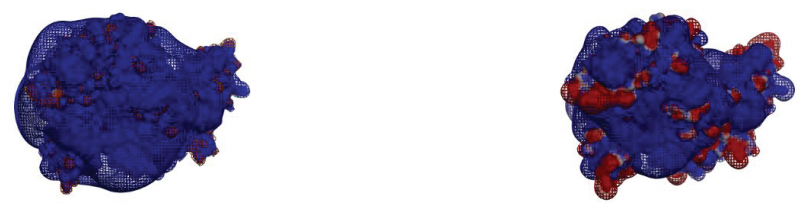

$\mathrm{pH}_{\mathrm{c}}=4.6 \quad 0 \mathrm{M}$

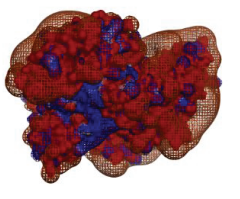

$\mathrm{pH}_{\mathrm{c}}{ }^{\prime}=7.3 \quad 0 \mathrm{M}$

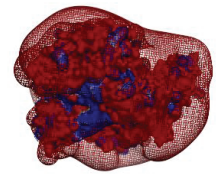

$\mathrm{pH}_{\phi}=8.7 \quad 0 \mathrm{M}$

$$
\mathrm{pH}_{\mathrm{c}}=4.6 \quad 0.15 \mathrm{M}
$$

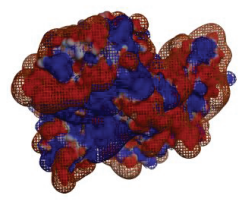

$\mathrm{pH}_{\mathrm{c}}{ }^{\prime}=7.3 \quad 0.15 \mathrm{M}$

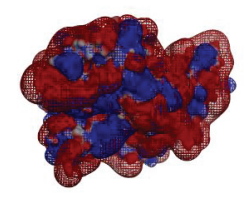

$\mathrm{pH}_{\phi}=8.7 \quad 0.15 \mathrm{M}$
Figure 5: Electrostatic potential contour $+1 \mathrm{kT} / \mathrm{e}$ (blue) and $-1 \mathrm{kT} / \mathrm{e}$ (red) around the BSA unimer at different salt concentrations ([NaCl]= $0 \mathrm{M}$ and $0.15 \mathrm{M})$ and at $\mathrm{pH}$ transitions $\left(\mathrm{pH}_{\mathrm{c}}, \mathrm{pH}_{\mathrm{c}}{ }^{\prime}\right.$ and $\left.\mathrm{pH}_{\mathrm{f}}\right)$. Calculation was based on PDB ID of Bovine Serum Albumin (3V03 "unimer"). 
charged surface residues was increased and at $\mathrm{pH}=\mathrm{pH}_{\mathrm{c}}$ lower than $\mathrm{pI}$ the negatively charged character of a BSA chain in acid $\mathrm{pH}$ was shown by little "patches" in red. This demonstrated that BSA interacts with PEI even with positive net charges. Still, we noticed a significant effect of added salt (change of colors at surface of BSA), for example, at $\mathrm{pH} \geq 7.3$, the appearance of remarkable weak symmetry between positive and negative regions with regard to both shape and magnitude. Indeed, in this region of $\mathrm{pH}$, the protein prefers to bind to the polycation since it has a distinct sign of charges. Moreover, in the case of $\mathrm{pH}>\mathrm{pI}$ and at high salt concentration $(0.15 \mathrm{M})$, the Debye length $\left(\kappa^{-1} \approx 0.78 \mathrm{~nm}\right.$ ) is much less than the protein radius $R_{\text {protein }}$, indicating that all repulsions are screened. In fact, addition of salt acts to weaken attractions, corresponding to the decrease in affinity (35). Indeed, the change of color, i.e. charge sign, in presence of salt, at the surface of the protein (see Figure 5) explains well the shift founded in Figures 2 and 3. Still, in this region, the combination of short-range attractive interactions coupled with longue-range repulsive interactions is performed only if PEI binds to the negative domain of BSA.

Based on the analysis performed by Bowman et al., we treated theBSA protein, as a dipole of negative charge $Q_{-}$and positive charge $Q_{+}$with relative distances with polycation of charge $q_{+}$, are $R_{-}$and $R_{+}$, respectively. At $\mathrm{pH}>\mathrm{pI}, Q_{-}>Q_{+}$ and the electrostatic binding of the polycation requires $R_{-}<R_{+}$(36). The electrostatic interaction energy can be written as a sum of repulsive and attractive terms:

$$
U=\frac{q_{+}}{2 \varepsilon}\left(Q_{+} \frac{\exp \left(-\kappa R_{+}\right)}{R_{+}}-Q_{-} \frac{\exp \left(-\kappa R_{-}\right)}{R_{-}}\right)
$$

where $\varepsilon$ is the dielectric constant of solvent and $\kappa^{-1}$ is the Kuhn length.

The extremum $\kappa_{\text {ext }}$ corresponding to the maximum in binding energy at a screening length $\kappa^{-1}\left(\kappa^{-1}=\frac{1}{\kappa_{\text {ext }}}\right)$, can be determined from the first derivative of Eq. 10:

$$
\kappa_{\text {ext }}=\frac{\operatorname{In} \frac{Q_{+}}{Q_{-}}}{\left(R_{+}-R_{-}\right)}
$$

Taking the same procedures followed by Dubin (35), where the rate of charges $Q_{+} / Q_{-}$ranging from 1.2 to 1.5 , the estimated screen length $\kappa^{-1}$ ranging from $\frac{R_{\text {protein }}}{2}$ to $\frac{R_{\text {protein }}}{3}$. These two values are valid for charges that are not in direct contact with the binding site and located along the skeleton of polycation or far from the surface of BSA.

\section{Conclusion}

In this paper, we have investigated the interactions of BSA with various molar masses of a linear polycation (PEI) versus $\mathrm{pH}$ and salt concentration using a dynamic light scattering, turbidimetry and computer simulations. These simulations were used to estimate the influence of $\mathrm{pH}$ and salt on the surface charge distributions and on the electrostatic potential of protein.

No influence of the salt before the formation of the complex $\left(\mathrm{pH}<\mathrm{pH}_{\mathrm{c}}\right.$ on the mixture formed of BSA and PEI. Moreover, the molar mass of the polyethelenimine does not influence the hydrodynamic radius and the turbidity. By way of example where the $\mathrm{pH} \sim 6$ and for the two mixtures (BSA/PEI $(2.5 \mathrm{kDa})$ and BSA/PEI $(25 \mathrm{kDa})$ ), the $R_{\mathrm{H}} \sim 6 \mathrm{~nm}$, and the turbidity $\sim 10 . \mathrm{At} \mathrm{pH}=\mathrm{pHc}$, the Coulombic attraction forces between the concentrations of negative charges (i.e., the patches) of protein and other positively charged macromolecules could locally overwhelm the overall repulsions due to the overall positive charges of the two macromolecules at $\mathrm{pH}$ values lower than the $\mathrm{pHi}$ of the protein. Hence, the formation of macromolecular complexes is enabled. In addition, from the results mentioned before i.e. for $\mathrm{pH}>\mathrm{pH}_{\mathrm{c}}$ an increase in the size of the complex formed when the molecular mass of the polycations increases. However, two limiting cases to account for the influence of this parameter. Firstly, if the molecular mass of the polycation is too low, the interaction will be done by simple ion bridging rather than by the formation of intermolecular electrostatic complexes. Conversely, if the molecular weight is very high, the interaction will lead to the formation of precipitates rather than coacervates. Finally, the control of the charge density of the macromolecules provides a mean to regulate the stoichiometry of the macromolecules within the complexes.

Acknowledgments: This research was supported by the Ministry of Higher Education and Scientific Research in Tunisia (MHESRT).

\section{References}

1. Tharanathan R.N., Biodegradable films and composite coatings: past, present and future. Trends Food Sci Technol, 2003, 14, 71-78. 
2. Ocak B., Aslan A., Gülümser G., Utilization of Chromium-tanned leather solid wastes in microencapsulation. J Am Leather Chem Assoc, 2011, 106, 232-238.

3. Leissy G., Hector L.R., Maria L.V., Junior H., Reynaldo V., Immobilization of chitosan-modified invertase on alginatecoated chitin support via polyelectrolyte complex formation. Enzym Microb Technol, 2006, 38, 22-27.

4. Kokufuta E., Functional immobilized biocatalysts. Prog Polym Sci, 1992, 17, 647-697.

5. Porfiri M.C., Farruggia B.M., Romanini D., Bioseparation of alphaamylase by forming insoluble complexes with polyacrylate from a culture of Aspergillus oryzae grown in agricultural wastes. Sep Purif Technol, 2012, 11-16.

6. Li T., Yang M., Electrochemical sensor utilizing ferrocene loaded porous polyelectrolyte nanoparticles as label for the detection of protein biomarker IL-6. Sensor Actuat B-Chem, 2011, 158, 361-365.

7. Muller M., Brissova M., Rieser T., Powers A.C., Lunkwitz K., Deposition and properties of polyelectrolyte multilayers studied by ATR-FTIR spectroscopy. Mater Sci Eng C, 1999, C8-C9, 163-169.

8. Chang T.M., Artificial cells with emphasis on bioencapsulation in biotechnology. Biotechnol Annu Rev, 1995, 1, 267-295.

9. Trabelsi S., Aschi A., Othman T., Gharbi A., Complex formation between ovalbumin and strong polyanion PSSNa: Study of structure and properties. Mater Sci Eng C, 2014, 42, 295-302.

10. Othman M., Aschi A., Gharbi A., Polyacrylic acids-bovine serum albumin complexation: Structure and dynamics. Mater Sci Eng C, 2016, 58, 316-323.

11. Dubin P.L., Gao J., Mattison K., Protein Purification by Selective Phase Separation with Polyelectrolytes. Sep Purif Methods, 1994, 23, 1-16.

12. Griffith A., Glidle A., Cooper J.M., Probing enzyme polymer biosensors using X-ray photoelectron spectroscopy: determination of glucose oxidase in electropolymerised films. Biosens Bioelectron, 1996, 11(6-7), 625-631.

13. Xia J., Dubin P.L., Dautzenberg H., Light scattering, electrophoresis, and turbidimetry studies of bovine serum albumin-poly(dimethyldiallylammonium chloride) complex. Langmuir, 1993, 9, 2015-2019.

14. Kayitmazer A.B., Strand S.P., Tribet C., Jaeger W., Dubin P.L., Effect of polyelectrolyte structure on protein-polyelectrolyte coacervates: coacervates of bovine serum albumin with poly(diallyldimethylammonium chloride) versus chitosan. Biomacromolecules, 2007, 8, 3568-3577.

15. Antonov M., Mazzawi M., Dubin P.L., Entering and exiting the protein-polyelectrolyte coacervate phase via nonmonotonic salt dependence of critical conditions. Biomacromolecules, 2010, 11, 51-59.

16. Mattison K.W., Dubin P.L., Brittain I.J., Complex Formation between Bovine Serum Albumin and Strong Polyelectrolytes: Effect of Polymer Charge Density. J Phys Chem B, 1998, 102, 3830-3836.

17. Mattison K.W., Brittain I.J., Dubin P.L., Protein-Polyelectrolyte Phase Boundaries. Biotechnol Prog, 1995, 11, 632-637.

18. Herlem G., Lakard B., Fahys B., Recent research developments in electroanalytical chemistry. Trivandrum, 2001, 3, 21-33.
19. Herlem G., Lakard B., Ab-initio study of the electronic and structural properties of the crystalline polyethyleneimine polymer. J Chem Phys, 2004, 120, 9376-9382.

20. Vicent M.J., Duncan R., Polymer conjugates: Nanosized medicines for treating cancer. Trends Biotechnol, 2006, 24, 39-47.

21. Kasprzak A., Popławska M., Bystrzejewski M., Łabędź O., Grudziński I.P., Conjugation of polyethylenimine and its derivatives to carbon-encapsulated iron nanoparticles. RSC Adv, 2015, 5, 85556-85567.

22. Daintith J., Oxford Dictionary of Chemistry. Oxford University Press Publisher, Oxford University, 2008.

23. Siegert A.J.F., On the fluctuations in signals returned by many independently moving scatterers. MIT Radiation Lab, Report No. 465, 1943.

24. Chu B., Laser Light Scattering (2nd ed.). Academic, New York, 1991.

25. Kaibara K., Okazaki T., Bohidar H.B., Dubin P.L., pH-induced coacervation in complexes of bovine serum albumin and catinic polyelectrolytes. Biomacromolecules, 2000, 1, 100-107.

26. Clitor J.F., Souza E.E., Garcia R., Effects of salt and protein concentrations on the association and dissociation of ovalbumin-pectin complexes. Food Hydrocolloids, 2015, 47, 124-129.

27. Bram L.H.M., Sperber B., Henk A., Schols C., Martien A., Cohen S., et al., Influence of the overall charge and local charge density of pectin on the complex formation between pectin and $\beta$-lactoglobulin. Food Hydrocolloids, 2009, 23, 765-772.

28. Salis A., Bostr M., Medda L., Cugia F., Barse B., Parsons D.F., et al., Measurements and Theoretical Interpretation of Points of Zero Charge/Potential of BSA Protein. Langmuir, 2011, 27, 11597-11604.

29. Tolstoguzov V.B., Thermodynamic Aspects of Food Protein Functionality, Food hydrocolloids: structures, properties and functions (K. Nishinari and E. Doi, Eds.). Plenum Press, New York, 1994, pp. 327.

30. Tolstoguzov V.B., Protein-polysaccharide transitions. Food Sci Tech-Brazil, 1997, 80, 171-198.

31. Curtis K.A., Miller D., Millard P., Basu S., Horkay F., Chandran P.L., Unusual Salt and pH Induced Changes in Polyethylenimine Solutions. PLoS One, 2016, 11(9), e0158147.

32. Li H., Robertson A.D., Jensen J.H., Very fast empirical prediction and rationalization of protein pKa values. Proteins, 2005, 61, 704-721.

33. Naz H., Shahbaaz M., Bisetty K., Islam A., Ahmad F., Hassa Md. I., Effect of $\mathrm{pH}$ on the Structure, Function and Stability of Human Calcium/Calmodulin-Dependent Protein Kinase IV: A Combined Spectroscopic and MD Simulation Studies. Biochem Cell Biol, 2016, 94(3), 221-228.

34. Jachimska B., Wasilewska M., Adamczyk Z., Characterization of globular protein solutions by dynamic light scattering, electrophoretic mobility, and viscosity measurements. Langmuir, 008, 1:24(13), 6866-6872.

35. Seyrek E., Dubin P.L., Tribet C., Gamble E.A., Ionic Strength Dependence of Protein-Polyelectrolyte Interactions. Biomacromolecules, 2003, 4, 273-282.

36. Bowman W.A., Rubinstein M., Tan J.S., Polyelectrolyte-Gelatin Complexation: Light-Scattering Study. Macromolecules, 1997, 30, 3262-3270. 